included, especially at times of the day when convection currents are not in evidence in the lower atmosphere, otherwise double observations by day and by night were obtained with different base-lines of approximately half a mile, one mile, and one and a half miles in length. Some hundreds of ascents were observed, of which a fair proportion reached a height between 9 and i $\mathrm{km}$., only 30 per cent. failing to reach the $4-\mathrm{km}$. level.

The data are admittedly insufficient to determine a diurnal oscillation, but Dr. van Bemmelen is fairly satisfied with the result for the semi-diurnal one. The east and north components are treated separately, and it is found that the former has a greater amplitude than the latter, and also a better determined phase. Gold's theoretical results for the lower layers are confirmed (Phil. Mag., vol. xix.). The phase of the east component diminishes up to $4 \mathrm{~km}$., and probably increases above that height, showing a fairly close analogy with the vertical oscillations. W. W. B.

\section{RECONSTRUCTION IN FRANCE.}

THE issue of the Revue Scientifique for April 13 contains evidence that our French neighbours are discussing the problems of reconstruction on much the same lines as we are. In an article on agriculture in I9I7, M. Albin Haller, president of the Académie d'Agriculture, deals with the present effects of the war on agriculture and the outlook after the war, particularly in regard to the supply of artificial manures. He points out that war conditions have led to a diversion of the supply of nitrogenous manures to the manufaoture of explosives, and that after the war it will be necessary to make up for the lost fertility of the soil by State efforts in the direction of stimulating the home supply of nitrogenous fertilisers from such sources as the by-products of gas- and coke-making, or even from special plants devoted to nitrogen fixation. In regard to the latter, he rightly points out that the feasibility may depend upon the harnessing of the waterfalls of the country-a point that we might well take to heart when we consider the immense possibilities of the Highlands of Scotland in this direction. M. Haller also throws out suggestions in regard to the future supply of phosphatic fertilisers, again touching a problem which is engaging attention here. The faot that the State now controls the production of sulphuric acid, and that, owing to its command over Australian zinc "concentrates," it may be able to market the acid as a waste product, inevitably suggests State enterprise in the future production of fertilisers as an adjunct to its food-production campaign.

An article in the same issue by M. Brucker, Principal of the Lycée de Cherbourg, entitled "L'Education de l'esprit scientifique," may be paralleled by the Report of the Committee appointed by the Prime Minister to inquire into the position of natural science in the educational system of Great Britain. It is perhaps characteristic of the two nations that, whereas the former is largely devoted to a discussion of the abstract and logical principles of scientific education-whether, for example, the methods should be synthetic or analytic-.-the latter concerns itself largely with the concrete problems of curricula, supply and training of teachers, etc. One rarely reads the writings of an educated Frenchman without having some cause to envy his possession of a language which is such an elegant vehicle for the picturesque, and, at the same time, precise expression of ideas. Such an instance can be cited in $M$. Brucker's characterisation of scientific definition as "une lutte contre le psittacisme," or, when quoting another writer, he speaks of "battant la paille des mots pour en faire tomber le grain des choses." May we commend the latter operation to our politicians?

B.

\section{RADIATION AND THE ELECTRON.1}

II.

I $\mathrm{N}$ spite of the credentials which have just been presented for Einstein's equation, we are confronted with the extraordinary situation that the semi-corpuscular theory out of which Einstein got his equation seems to be wholly untenable, and has, in fact, been pretty generally abandoned, though Sir J.J. Thomson ${ }^{2}$ and a few others ${ }^{3}$ seem still to adhere to some form of æther-string theory-that is, to some form of theory in which the energy remains localised in space instead of spreading over the entire wave front.

Two very potent objections, however, may be urged against all forms of æther-string theory, of which kinstein's is a particular modification. 'The first is that no one has ever yet been able to show that such a theory can predict any one of the facts of interference. The second is that there is direct positive evidence against the view that the rother possesses a fibrous structure. For if a static electrical field has a fibrous structure, as postulated by any form of æther-string theory, "each unit of positive electricity being the origin, and each unit of negative electricity the termination, of a Faraday tube," " then the force acting on one single electron between the plates of an air condenser cannot possibly vary continuously with the potential difference between the plates. Now in the oil-drop experiments (Phys. Rev., vol. ii.[1913], p. Iog) we actually study the behaviour in such an electric field of one single, isolated electron, and we find, over the widest limits, exact proportionality between the field strength and the force acting on the electron as measured by the velocity with which the oil drop to which it is attached is drasged through the air.

When we maintain the field constant and vary the charge on the drop, the granular structure of electricity is proved by the discontinuous changes in the velocity, but when we maintain the charge constant and vary the field the lack of discontinuous change in the velocity disproves the contention of a fibrous structure in the field, unless the assumption be made that there are an enormous number of æther strings ending in one electron. Such an assumption takes all the virtue out of an æether-string theory.

Despite, then, the apparently complete success of the Einstein equation, the physical theory of which it was designed to be the symbolic expression is found so untenable that Einstein himself, 1 believe, no longer holds to it, and we are in the position of having built a very perfect structure and then knocked out entirely the underpinning without causing the building to fall. It stands complete and apparently well tested, but without any visible means of support. These supports must obviously exist, and the most fascinating problem of modern physics is to find them. Experiment has outrun theory, or, better, guided by erroneous theory, it has discovered relationships which seem to be of the greatest interest and importance, but the reasons for them are as yet not at all understood.

It is possible, however, to go a certain distance towards a solution and to indicate some conditions which must be satisfied by the solution when it is found. For the energy $h v$ with which the electron is found by experiment to escape from the atom must have come either from the energy stored up inside the atom or else from the light. There is no third possibility.

1 Address to the Section of Physics and Chemistry of the Franklin Institute, Philadelphia, on January $4 .{ }^{1917}$, by Prof. R. A. Millikan, professor of physics in the University of Chicago. The substance of this lecture has since been incorporated into a book recently issued by the University of Chicago Press, entitled "The Electron." Continued from p. 237.

3 "Modern Electrical Theory" (Cambridge University Press, r913), p. 248 .

NO. 2535 , VOL. IOI]

"J. J. Thomson, " Electricity and Matter," p. 9. 